\title{
Weather Derivatives-Are you willing to hedge the monsoon With special reference to Agriculture Sector in India
}

\author{
Dr Neha Arora \\ Asst Professor \\ Shri Ram Murti Smarak College of Engineering \& Technology \\ Bareilly \\ aaroraneha@gmail.com
}

\begin{abstract}
With drought looming large over 14 meteorological sub-divisions, spare a thought for the planted crops that are in grave danger. For the farmers in Maharashtra, Andhra Pradesh, Karnataka and Uttrakhand this monsoon has brought everything except the much-needed moisture. "Come rainy season and nearly 59 per cent of the Indian population, the people dependent on agriculture, keep their fingers crossed. Some pray to the rain God to ensure that it does not pour so hard that their crops get destroyed. On the other hand, in some villages, the farmers tie two frogs to a pole and get them married, a superstition which is supposed to bring good rainfall," Superstitions apart, the seriousness of weather cannot be overemphasised. India, as a country, faces great variations in weather conditions due to its diverse geographical structure. While some places are hit by flood, some others by drought, rising temperatures are scaling new peaks and chilling winters are breaking old records. Such diversity in weather conditions affects the business processes of many industries directly or indirectly giving agriculture the greater break. Is weather derivates the one of the solutions to the sight for agricultural risk bearing safety? This paper aims to examine the state of risk management in agriculture of India, evaluate the effectiveness of weather derivatives as risk management tools and basic framework required to hedge them.
\end{abstract}

Keywords: Climatic hazards, Risk management, Derivative markets, Hedging, India, Agriculture

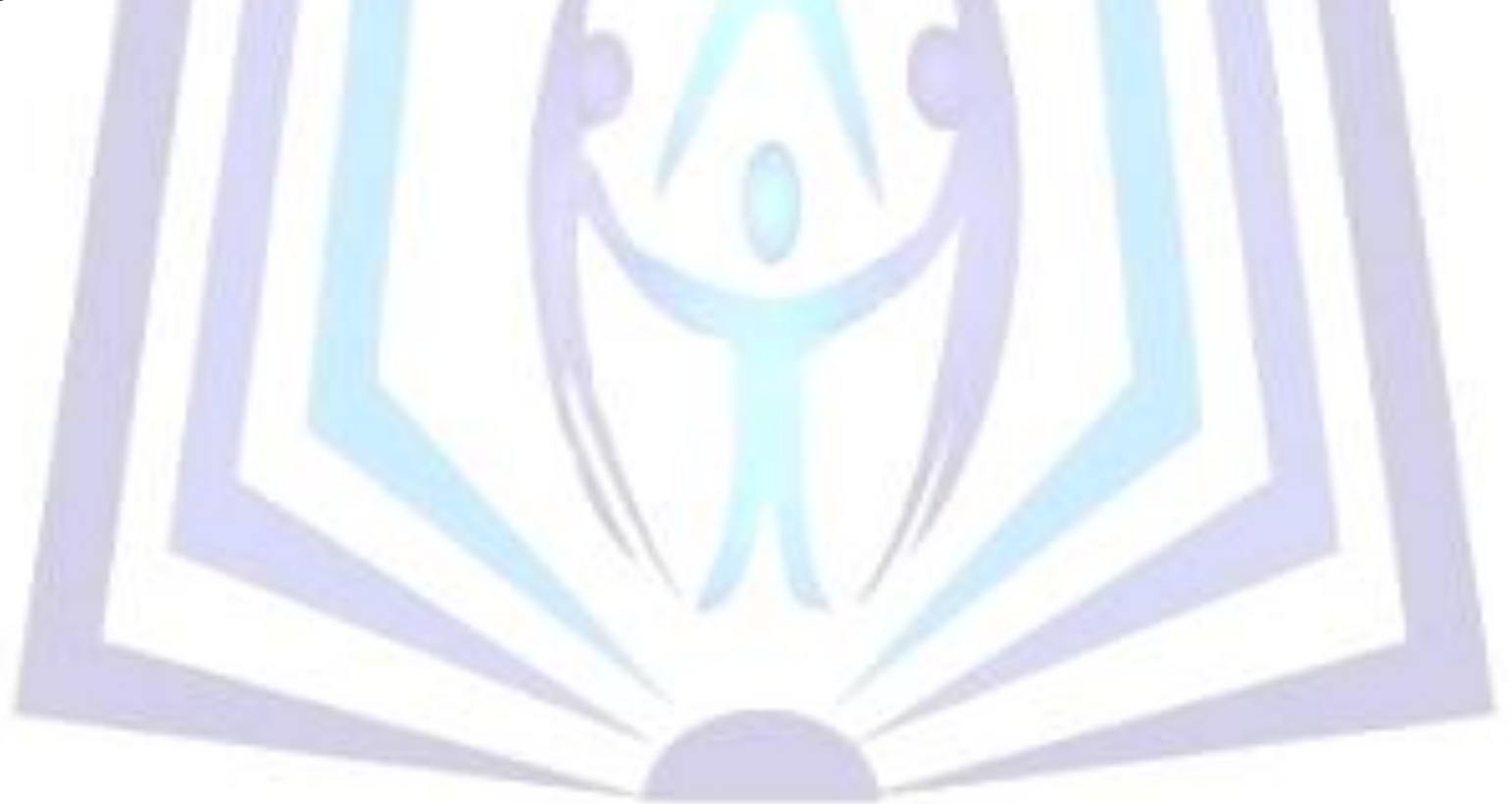

\section{Council for Innovative Research}

Peer Review Research Publishing System

Journal: International Journal of Management \& Information Technology

Vol. 6, No. 3

editor@cirworld.com

www.cirworld.com, member.cirworld.com 


\section{INTRODUCTION}

In India, agricultural risks are exacerbated by a variety of factors, ranging from climate variability and change, frequent natural disasters, uncertainties in yields and prices, weak rural infrastructure, imperfect markets and lack of financial services including limited span and design of risk mitigation instruments such as credit and insurance. These factors not only endanger the farmers' livelihood and incomes but also undermine the viability of the agriculture sector and its potential to become a part of the solution to the problem of endemic poverty of the farmers and the agricultural labour. The criticality of agriculture in the rural transformation and the national economy seen along with its structural characteristics require substantial governmental and financial sector interventions to ensure household food and nutritional security as also to generate savings and investments. The problem presently is not the price discovery but issues like the current agricultural market structure in India, lack of holding capacity faced by the farmers and lack of bargaining capacity. One can engrossed to find the possible solution to these problems in the Spot Commodity Exchange where all parties farmers, buyers, and arhatiyas - are electronically linked and certified to enable seamless transactions. In this backdrop, this paper attempts to highlight the concept of weather derivatives and its relevance to Indian agriculture in managing the risk. Also, the paper briefly discusses the risks involved in agriculture and the earlier attempts to mitigate the same which has restricted to insurance schemes, the importance of weather derivatives and its variants including an attempt on the recent Indian experience besides the cross country experience.

\section{RISK FINANCING \& LOSS SHARING IN INDIAN AGRICULTURE ENVOIRNMENT}

The role of weather in agriculture and other industries is creating an emerging market for weather based insurance and derivatives product. Indian farmers mainly depend on the rains for irrigation of their crops. Meager rainfall leads to drought while excess rainfall causes floods. Both droughts and floods may lead to large-scale damage of crops, a failed harvest, a huge loss and inflation. Other natural disasters such as cyclones also play havoc with crops. No one is able to control the weather or make accurate predictions about how the weather will turn. It is absolutely necessary to manage such risks if impossible to mitigate them. Besides, such natural risk, other risks that are involved in the agricultural environment includes changes in domestic and international agricultural policies, carrying capacity, extent of subsidies, incentives, tariffs and credit facilities are amenable to the control of human factor. In other words, the weather can have both a direct influence, reflected in agricultural losses, and an indirect impact noticed on the economic growth in case of high dependency on the farming sector. So to bear the different risks involved there exist different types of instruments existing in the financial contract market to share the losses occurred due to weather. This can be summarized in the Figure 1 below:-

\begin{tabular}{|l|l|}
\hline Approaches & Examples Of Instruments \\
\hline $\begin{array}{l}\text { Non Market Risk Transfer } \\
\text { Collective loss sharing) }\end{array}$ & $\begin{array}{l}\text { Government Assistance, } \\
\text { Kinship Arrangements, } \\
\text { Some mutual insurance arrangements, } \\
\text { Donor Assistance }\end{array}$ \\
\hline $\begin{array}{l}\text { Market Risk Transfer } \\
\text { ( ex ante risk financing ) }\end{array}$ & $\begin{array}{l}\text { Insurance and reinsurance } \\
\text { Weather Derivatives }\end{array}$ \\
\hline $\begin{array}{l}\text { Intertemporal Risk Spreading } \\
\text { ( ex ante risk financing ) }\end{array}$ & $\begin{array}{l}\text { Contingent Credit } \\
\text { Reserve Fund }\end{array}$ \\
\hline
\end{tabular}

\section{WHAT IS FINANCIAL CONTRACT FOR WEATHER VARIABLES}

A financial weather contract can be defined as a "weather contingent contract whose payoff will be in an amount of cash determined by future weather events. The settlement value of these weather events is determined from a weather index, expressed as values of a weather variable measured at a stated location" (Dischel and Barrieu 2002).

A financial weather contract can take the form of a weather derivative (WD) or of a weather insurance (WI) contract. While the differences between the two types of contracts might be important from regulatory and legal viewpoints, from an economic perspective both instruments share the common feature of being triggered by an underlying weather index. In discussing agricultural policy and risk management tools, this is probably the most relevant aspect. From now on we will therefore refer to Weather Derivatives, highlighting the differences between the two types of instruments only when necessary. More relevant to the current discussion is the difference between a weather financial contract and a traditional insurance contract on a weather variable (e.g., hail insurance). In traditional insurance contracts, indemnities are paid only after actual damages are quantified by proper loss adjustments, and not simply upon the occurrence of the specific state of nature. This is an important difference that, according to the specific circumstances, can make one of the instruments more attractive than the other. 


\section{HISTORY OF WEATHER DERIVING VARIABLES}

What should have the weather been like? Is of the most common question which is discussed where weather is concerned as term weather is more often associated with weather forecast (Randalls, 2005). In the recent years we have witnessed the growing importance of the implementation of Kyoto protocol among all nations. Due to the phenomenon of global warming and emissions of greenhouse gasses from factories are contributing a great deal to the changes in weather conditions. Weather comes in various forms and affects companies both geographically and seasonally. When weather patterns significantly vary from its usual norms the effects can be catastrophic. These adverse weather conditions cause risk and uncertainty (Dosi.and Moreto, 2001). As estimated by Chicago Mercantile Exchange almost $20 \%$ of the US economy is directly on indirectly affected by weather. Historically, the weather was perceived to unchangeable until the emergence of an innovative instrument where weather was commoditised into a financial instrument today more popularly known as weather derivatives (Castree, 2003).

\subsection{Basic Introduction To The Concept Of Weather Derivatives}

The weather derivatives industry is relatively young. This derivatives sector began to develop in 1997, as a result of the severe weather events of El Niño. The El Niño events of 1996-1998 were the first such major climate forecasts that the meteorological community forecasted correctly. The El Niño winter of 1997-1998 was forecasted to be unseasonably mild. This caused numerous companies that had earnings tied to weather to realize the importance of hedging their seasonal weather risk. During this time, the insurance industry was in a position to make available a sufficient amount of capital to hedge weather risk. There were a large number of options with payouts tied to weather events that were written by insurance companies, which increased liquidity for the development of a monthly and seasonal market for weather derivatives. As a result of these events, the weather derivatives market grew rapidly into a thriving over-the-counter market (Considine, 2006). However, continued growth was limited due to the credit risk associated with an over-the-counter market.

The world's first exchange-traded weather derivative began trading on September 22, 1999, at the Chicago Mercantile Exchange (CME). Weather derivatives originated initially as over-the-counter (OTC) products in the US less than two years ago. However, as participants sought greater liquidity, price discovery and transparency, the market had to move to an exchange-trading environment. The CME has initially listed temperature-related heating degree-day (HDD) index futures for four US cities but plans to add cooling degree-day (CDD) indices as well at more locations.

A degree-day (DD) has emerged as a common measure of temperature, and measures the deviation of a day's average temperature from the reference. An HDD occurs when the average temperature is below the reference and a CDD when the average temperature is above. The CME contracts are based on an index that measures the extent and frequency that the average temperature drops below 65 degrees Fahrenheit (the reference) cumulated monthly across the relevant city. The futures contracts pay $\$ 100$ per each point movement in the index. Earth Satellite Corporation, an independent entity, calculates the HDD index ensuring transparency and independence in the benchmark. Weather derivatives are financial products that enable an organisation to offset the financial risk due to a weather variable. They emerged as an offshoot of insurance. Insurance is expensive and requires a demonstration of loss (of assets or of profits).

\section{TRADING WEATHER DERIVATIVES IN INDIA}

Many agricultural regions in the developing world are subject to severe droughts, which can have devastating effects on household incomes and consumption, especially for the poor. To protect consumption, rural households engage in many different risk management strategies - some mainly risk-reducing and some simply coping devices to protect consumption once income has been lost. An important limitation of these traditional risk management strategies is their inability to insure against covariate risks and they are also costly. The absence of formal credit and insurance institutions, which offer an efficient alternative by overcoming regional covariance problems and reducing the cost of risk management, amounts to a market failure. Past research has paid much more attention to the supply-side reasons for this market failure than to the demand side question of whether there exist financial instruments that farmers want and would be willing to pay for. India has a long and chequered history of commodity derivative trading, spanning over 130 years. The commodity derivative exchanges witnessed several ups and downs for the past 13 decades, with a booming phase of unbridled free futures trading in as many as 300 markets during the pre-independence era, followed by a ban on such trading for almost a decade after the outbreak of the Second World War in 1939. Subsequent to independence in 1947, the then Government of Bombay enacted the Bombay Forward Contracts Act and permitted futures trading in cotton and oilseeds under the auspices of the recognized associations. Outside Bombay Presidency, commodity futures trading was also revived, but remained free and unregulated except by the exchanges organizing such trading.

With the Constitution of India coming into force on January 26, 1949, the subject of futures trading came under the Union List. As a result, the Government of India brought on the Statute Book the Forward Contracts (Regulation) Act, 1952 (FCRA), and established the Forward Markets Commission (FMC) in 1953. Under the FCRA, futures trading came to be allowed in select agricultural commodities and their products under the auspices of associations recognized by the Government of India. By mid-1960s, around 30 associations were recognized for trading in about a score of commodities. Trading was subject to severe regulatory measures. But no sooner the markets began to bloom with some activity, the government turned volte-face, and proscribed futures trading in almost all major food crops in the fond hope of restraining the raging inflation in the economy.

Following the launch of economic reforms in the early 1990s, and especially after India signed the General Agreement on Trade and Tariffs (GATT) to enter the World Trade Organization (WTO), the World Bank and UNCTAD submitted a joint report to the Government of India recommending revival of futures trading in farm commodities and their products to render trade in such commodities competitive in the world markets after the envisaged removal of trade and non-trade 
barriers. As a result, futures trading were revived, after a lapse of nearly three and a half decades, towards the close of the $20^{\text {th }}$ century. The onset of the new millennium thereafter witnessed the setting up of three new national commodity exchanges, which were permitted to trade in commodities of their choice, unlike the traditional regional and single commodity exchanges that traded in one or few closely related commodities only. At present, there are almost two dozen commodity exchanges, including three national exchanges, trading in as many as 100 commodities together.

The first weather insurance pilot in India was set in July 2003 (monsoon- based weather insurance) in Andhra Pradesh state by Mahindra Shubhlabh, ICICI Bank, ICICI Lombard and Basix. Basix launched this weather insurance programme through its local area bank KSB (Krishna Bhima Samruddhi Local Area Bank) in Maboobnagar. Local area banks are limited to operations in three adjacent districts and therefore face limited natural portfolio diversification, which helped to convince KSB that weather insurance contracts for its borrowers could mitigate the natural default risk inherent in lending in drought prone areas such as Maboobnagar, at the extreme Eastern end of AP, bordering Kamataka. The district has experienced three consecutive droughts during 2000-2003.

KSB bought a bulk insurance policy from $\mathrm{ICICl}$ Lombard and sold around 300 individual farmer policies for three categories of groundnut and castor farmers, small, medium and large10. Premium rates are Rs.456 for the small farmers with a liability of Rs.14250, medium farmers pay Rs.600 with a maximum liability of Rs.20000 and large farmers pay Rs.900 for a liability of Rs.20000. At the pilot stage KSB decided to limit liability per farmer rather than imposing per acre limits in order to manage overall liability. KSB sought to sell policies to up to 300 farmers for each of the two-targeted crops during the pilot stage. Farmer's uptake was immediate, with around 100 farmers signing up on very first day. KSB and $\mathrm{ICICI}$ Lombard opted for a weighted and capped rainfall index, which means that the maximum rainfall counted per sub-period is limited to $200 \mathrm{~m}$ and more critical periods for the plant growth are more heavily weighted than others. Informal interviews with 15 contracted farmers revealed that they were well aware of the rainfall based index nature of the contracts and the associated basis risk (Hess 2003). They also understand the two step payout structure of the policy and the fact that the liability limit is a theoretical number and historical maximum payouts are around 3025 and would have occurred in 2002 and 1997. Thus, the premium rate at that level was around 15\%. Nevertheless, the farmers appear to value the quick payout of the weather policy, which distinguishes it from the federal crop insurance policy in India. However, farmers preferred claim calculation based on absolute shortfall in millimetres rather than in percentiles (Sinha 2004). They also had problem with the rain gauge station which was located at a district headquarter. They also preferred a simple linear relationship between the rainfall and the claim amount. They were unable to appreciate the trigger points and different slab rates. Farmers like to have phase-wise payouts subject to the maximum limits. KSB decided that only borrowing farmers could buy weather insurance policies. Eventually KSB contemplates to lower the interest rate for these farmers due to the reduced default risk. Basix/KSB has also designed policies for Soya farmers in MP, Ujjain and UP, A1igarh. One of the top 5 reinsures in the world has agreed to reinsure this entire weather insurance portfolio.

The groundnut rainfall contract for Mahboobnagar is clearly associated with an insurable loss. This has been achieved through the weights used in the construction of the rainfall index and the relationship between the payoffs and the level of the index. The weights have been chosen to maximise the correlation between the rainfall index and groundnut yield in the region. The payoff pattern is supposed to capture the increasing severity of losses with progressive rainfall deficiency. These features tend to increase the complexity of the product and make it difficult for the farmers to understand (Sinha 2004). However, if the weights were removed and the payoff made linear the product would become closer to a derivative. Reinsurance would also be more easily available for this product since solely the rainfall, independent of the area crop yield, determines the payoff.

The AIC also introduced Varsha Bhima as pilot project in about 25 rain gauge stations across four states during kharif 2004 season (summer). The product included insurance based on seasonal rainfall, sowing failure, rainfall distribution index, agronomic optimum index and catastrophe cover. The scheme has been withdrawn after its maiden trail markets within their countries. A critical element for encouraging the use of weather risk markets in developing countries is for governments to provide access to their meteorological data and make the necessary investments in their weather stations in order to ensure accurate and tamper-proof measurements. International weather trading companies stand to benefit from including developing countries into their activities because they achieve diversification of the weather risks they cover on a global level (Skees, Hazell and Marinda 1999). This may contribute to reducing the overall risk of their weather portfolio and reduce the overall costs of covering weather risks. Finally, understanding and modelling the relationship between economic losses and weather events will be critical in designing tailored weather products that meet the requirements for various agricultural users (Skees 2001). Developing countries have a long way to go before real weather markets are developed and put in place. The pre-conditions are many to fulfil before the nail is put in the wood.

In 2005 National commodity and derivative exchange of India as well as Multi commodity Exchange of India provide for a trading platform for weather in India. The index will be set at 18 degree Celsius or 24 degree Celsius depending upon the location. As explained by Mr. Kumbhat, the HDD index for the contract period would be the sum of high-degree days for the month or the season. If we assume the daily average temperature on April 1 is 24 degrees Celsius and 23 degrees Celsius on April 2, the HDD index for April 1 would be six degrees Celsius(24-18=6) and five degrees Celsius for April 2 $(23-18=5)$. Then he total index value on the $2^{\text {nd }}$ of April would be a total of 11 degrees Celsius $(6+5)$.

\section{WHY WEATHER DERIVATIVE IS WANTED IN INDIA}

India is mainly an agricultural economy; the agricultural section mainly depends on monsoon. If there is a bad monsoon, it results into crop failure. This results into a sharp decline in the agricultural production and also affects rural consumption. Weak rural demand also has an effect on the demand of goods in the urban areas and there is a weak demand for good and services in the urban area. As a result the industrial production suffers, reducing the formation of the gross capital and hence, the entire economy slows down sharply. This also indicates that if there is any change in the agricultural sector of 
the country, it has a multiplier effect on the over all economy of the country. This can be better understood with the help of a diagram given below:

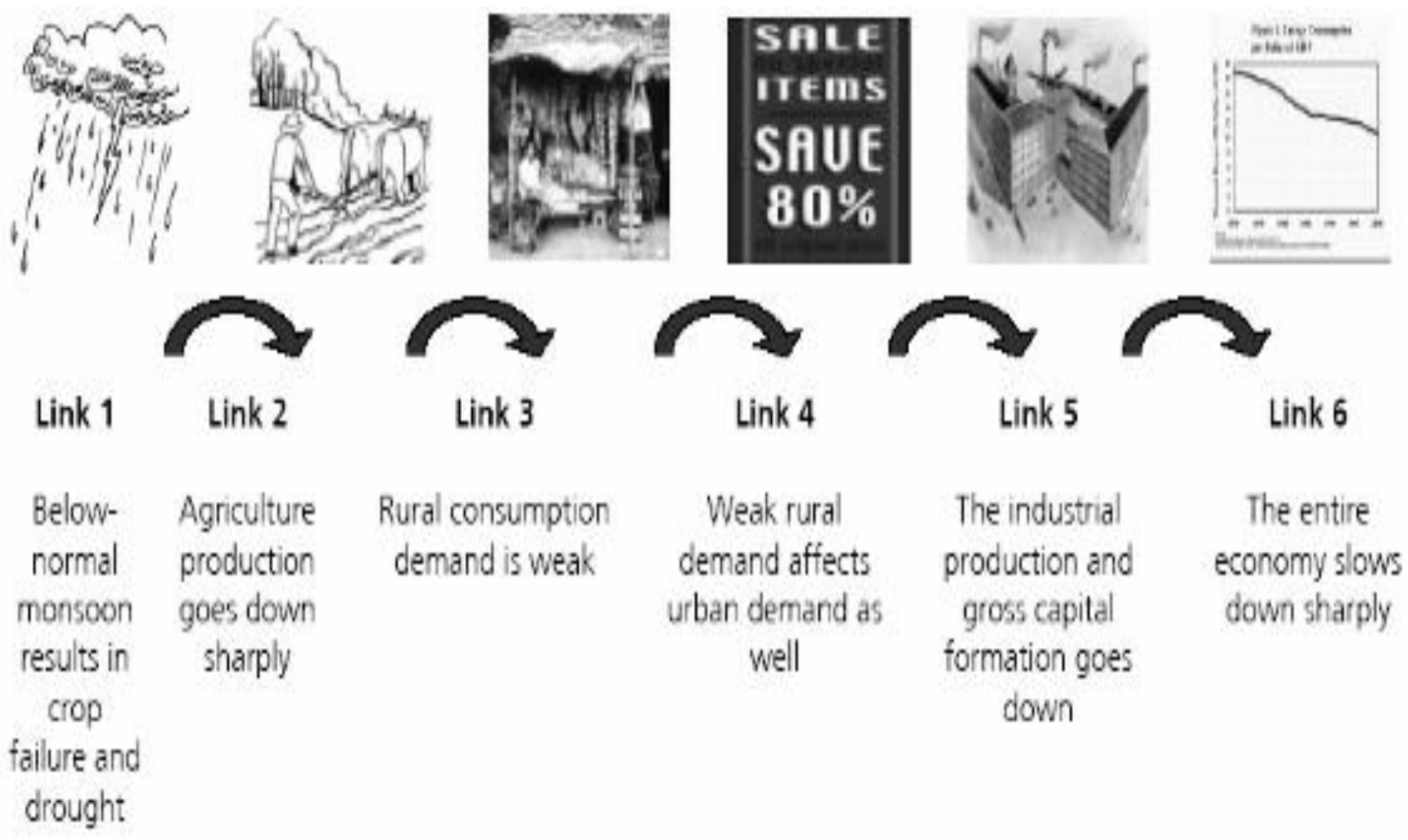

Weather Risk Management Services Private Limited which is a weather insurance company, has launch a trading platform for weather derivatives in the country, and estimates transactions worth \$30 billion within a year 2011.

The role of weather risk management service Private Ltd is to create a need spot market and also build an active trading platform for futures and option in India. Their main job is to make available developing technology in order to resolve the key constraint and make real time weather data available for long time period, to provide decision support systems for major customer. The company also intends to develop the secondary market along with a primary market, by launching weather indices in key regions. Approaching Commodity funds, Agri-funds, Rainfall speculators and international trading funds and encourage them to participate actively in the weather market. They are also making attempts to make changes in the regulations which will allow the banks as well as other financial institutions to trade in weather market.

As mentioned by Mr Kumbhat founder Weather Risk Management Services in the interview, even though there are commodity derivative as well as weather insurance available in the Indian market, there is still a need for weather derivatives. Commodity derivative takes care of only the price risk not volumetric risk. If a trader has to trade in volume of a commodity which he does not posses but might need in the future, he has to either trade in production indices, which are not available in India or trade in weather derivatives that are not available market, temperature indices are traded heavily. In India $90 \%$ of the weather market comprises of the agricultural sector and hence the weather index that is going to be launched in India is going to be a temperature and well as precipitation.

If weather insurance companies are allowed to trade on the weather market in India, then one can transfer their risk from weather insurance market to weather derivative market. The second option is to create a independent entity like a weather fund that will take the risk of both the insurance market and also trade in commodity market, which will help to create an arbitrage between the two markets. For example, if a framer has a deficit rainfall risk and there is another trader who has bought an option and will gain from deficit rainfall i.e. he has an excess rainfall risk, then an independent entity like a weather fund can take the risk of both the farmer as well the trader an create an arbitrage, providing a better rate to the insurance company.

\section{SCOPE OF WEATHER DERIVATIVES IN INDIAN AGRICULTURE SECTOR}

A substantial amount of weather derivative market in India constitutes of the agricultural sector. Most of the weather insurance in India, which is again restricted to agriculture, is in the form of a derivative. This is because there is no indemnification of loss, the claims are settled if the rainfall in below or above a certain level.

Indian production is highly dependent upon Monsoon rainfall. Only $40 \%$ of cultivated area has access to irrigation infrastructure although only $20 \%$ of this land is effectively irrigated. About $80 \%$ of the agricultural land depend on rainfall. India sustains $16 \%$ of world's population on $2,4 \%$ of land resource. Agriculture contributes $24 \%$ to the Indian GDP. Livelihood support to two-thirds of the population in India. 
During the last 40 years there were several droughts with rainfall deficit of over $10 \%-1972-73(-24 \%), 1979-80(-19 \%)$, $1982-83(-14 \%), 1987-88(-19 \%), 2002-03(-19 \%)$. In 2003 agricultural output decreased at 19\% due to severe drought in summer (-49\% of rainfall deviation). This led to 3,1\% reduction of agricultural GDP leading to drop in overall GDP growth. Agricultural insurance programs in India provide coverage for such crops as soybean, paddy, cumin, coriander, fenugreek, wheat, oranges, grapes, apples, peaches, etc.

Main risks for agricultural production include deficit/excess rainfall, high relative humidity, excessive temperatures prolonged dry spell, etc. Often risk come together in extreme combinations.

Since introduction of weather index insurance products in 2004, over 539,000 farmers have purchased weather insurance. There are 8 main direct insurers in India although 3 companies are actively working with weather index products Agricultural Insurance Corporation of India; ICICl Lombard General Insurance Company; and IFFCO Tokyo General Insurance Company. Banks are expected to join this segment after regulator signed-off on weather derivatives.

End-users who are present for weather derivatives deriving benefits include:

$>$ Farmers;

$>$ Corporations engaged in contract farming;

$>$ Tea and coffee producers;

$>$ Sugar producers;

$>$ wind farms;

$>$ Salt producers;

$>$ Bio-diesel plantations.

Insurance products are distributed through banks, insurance agents, brokers, cooperatives, micro-finance institutions, kiosk in rural areas, NGO's and self-help groups.

The most critical periods for summer crops are 12 weeks from mid-July till beginning of October, when crops require high water supply. This corresponds to vegetative and reproductive stages. The average water consumption is $180 \mathrm{~mm}$ (vegetative stage) and $190 \mathrm{~mm}$ (reproductive stage) during this period. Insufficient rainfall results in dramatic crop yield reduction or even total loss.

Weather index derivative products currently offered to the producers provide protection at different strike levels. Derivatives companies designed various index structures to better suit water requirements of the crops. Purchasing weather index derivative, producers can assure they will get compensation at the level of about $70 \%$ of the average crop yield. In the average the insurance companies compensate farmers with 10 Rs per $\mathrm{mm}$ of deficient or excessive rainfall. First weather index transactions were done in 2004 with BASIX microfinance institution for Castor and Groundnut crops in Mehbubnagar and Andra Pradesh against deficit rainfall. Insurance policies were purchased by 1500 small farmers.

Since then 36 facultative reinsurance contracts were closed reinsuring 272590 policies. Estimated market growth in 2007 (comparing with 2006) is about $200 \%$.

Insurance companies offer a viable alternative to the traditional crop insurance market which has the potential to extend beyond agricultural sector up into corporate end-user market.

Insurers are currently working on solutions for agro input providers, wind farms, tea plantations, hydro-power projects, sugar and salt production, contract farming, etc.

Since 2008 onwards since the first major disruption of weather has been started in last 5 years the distribution of weather index contracts in India was the following:

$>202142$ contracts on rainfall index $(74 \%)$;

$>46221$ contracts on temperature index (17\%);

19415 contracts on combined temperature and rainfall index $(7 \%)$;

4812 contracts on humidity index $(2 \%)$.

\section{IS INDIA REALLY MAKING THE FULL USE OF WEATHER DERIVATIVES TO HEDGE THE MONSOON}

Chasing The Monsoon literally pursue the rain god across the length and breadth of India. Yet, regulations governing Indian commodity exchanges have not come forward with mechanisms that would help farmers hedge against the weather, something that Weather Futures aim to do. We are waiting for the (Forward Contracts Regulation Act) amendments to get cleared in Parliament. When and whether it will happen is something that only the government can tell where in India only NCDEX already has rain indices, but this is only for purposes of display and dissemination of information.

While a thriving $\$ 1$ billion weather (betting) market exists, albeit illegally, in India, farmers, agro-processors, exporters and importers can participate in weather trading legally only when certain amendments are introduced to the Forward Contract Regulations Act.

As of now, Indian regulations do not define weather as a commodity, thus impeding trading. The law does not allow indices trading so a suitable instrument for Indian conditions like precipitation indices (related to rainfall) cannot be designed. It does not allow participation of financial institutions like banks, pension or mutual funds, which is a prerequisite in weather futures trading. If Financial Institutes participate, it will lead to a better hedging and price recovery. And the most important factor - options and swaps are not a part of the commodity market. If allowed, these instruments will attract corporate and Financial Institutes to participate, increasing volumes and making it possible to design a suitable weather contracts. Meanwhile, the Chicago Mercantile Exchange (CME), long recognising that nearly 56 per cent of the Indian economy depends on the weather, started weather futures in the country. The CME has various weather products related to temperature, rainfall and hurricane, among others. The exchange has now evinced interest in participating more in the Indian weather market and designs a pilot product for the same. Both CME and a few other US-based OTC exchanges are keen to participate in the Indian market, but India need to set up a proper infrastructure in place. It do not even have historical time series data giving weather-info in spite of having almost 580 weather stations in the country. 
The commodity exchange will probably lead the weather market-trading platform if it gets the necessary approvals. The trading platform would allow a participant to buy or sell the value of a temperature and rain (or precipitation) index at a specific future date. What this would mean is that power companies could trade in high degree days and low degree days contracts, in Mumbai for instance, estimating how much electricity would be consumed during those days, while farmers could use weather derivatives to hedge against poor harvests caused by deficient rainfall or drought.

While it may take time for the FCRA amendment to come though, exchange should set up infrastructure in place, which in this case is an automated weather station across the country. It has already roped in donor agencies like Food Foundation to fund the project cost, and established 500 weather stations across 10 Indian states.

Having such a infrastructure in place will help us to get the trading organised as we will have access to relevant information (like historical time series data, weather forecasts). The exchange also intends to start a weather fund with an initial corpus of Rs 15 crore, which would increase gradually, allowing it to take position in the trading platforms.

\section{CONCLUSION}

The concept behind a weather hedge is simple. It is a way to protect businesses from excessive costs or depressed demand due to unfavourable weather conditions. In this sense weather derivatives are an extension of traditional risk management tools such as options, futures and swaps (Geyser \& Van der Venter, 2001:2).

Until the advent of weather derivatives, exposure to the weather had been considered an inherent "business" risk in which only the risk to extreme weather events were hedged through the insurance market (Spillet,2001:34).As shareholders become increasingly aware of weather derivatives, firms will no longer be able to blame the weather for losses. Just as a firm can manage its currency exposure, so it can hedge its weather exposure. Add to the fact that over $70 \%$ of all companies suffer exposure from the weather and you have the beginnings of a major global market (Douglas-Jones, 2002b:27).

\section{Weather Derivative Structures}

\section{APPENDIX}

Weather derivatives are usually structured as futures, call/put options and swaps based on different underlying weather indices.

\section{Weather Futures}

The Chicago Mercantile Exchange (CME) offers trading with futures based on the Degree Day Index, which is the cumulative sum of daily, HDDs or CDDs during a calendar month. The HDD/CDD Index futures are agreements to buy or sell the value of the HDD/CDD Index at a future date. The notional value of one contact is $\$ 100$ times the Degree Day Index. On the CME the options on futures are European style, which means that they can only be exercised at the expiration date.

\section{Weather Options}

For generic weather options, the buyer of a HDD call pays the seller a premium at the beginning of the contract. In return, if the number of HDDs for the contract period is greater than the predetermined strike level, the buyer will receive a payout. The size of the payout is determined by the strike $(S)$ and the tick size (k). The tick size is the amount of money that the holder of the call receives for each degreeday above the strike level for the period. Often the option has a cap on the maximum payout unlike, for example, traditional options on shares.

\section{Weather Swaps}

Swaps are contracts in which two parties exchange risks during a predetermined period of time. In most swaps, payments are made between the two parties, with one side paying a fixed price and the other side paying a variable price. In most types of weather swaps, there is only one date when the cash flows are "swapped", as opposed to interest rate swaps, which usually have several swap dates. The swaps with only one period can therefore be thought of as forward contracts. Often the contract periods are single calendar months or a period such as January-March.

\section{Weather Measures}

As the weather market has been born out of demand for risk management products from the power industry, the most common and liquid products are designed to fit its requirements. However, the market has started to actively trade a growing number of indices tailored to the demands of all participants. All weather contracts are based on the actual observations of weather at one or more specific weather stations. Most transactions are based on a single station. However, some contracts are based on a weighted combination of readings from multiple stations while others on the difference in observations at two stations.

The underlying index of a weather derivative defines the measure of weather that governs when and how payouts on the contract will occur. There are many other indices used in the market. They are: Heating Degree Days (HDD)- This index is designed to measure how cold a period is compared to a standard temperature (18 degree $\mathrm{C}$ in Europe and 65 degree $\mathrm{F}$ in the US). This index is favoured by the power industry to hedge against a warm winter in which less power needs to be generated as compared to expectations. Cooling Degree Days (CDD)- Likewise the CDD index is used to measure how warm a period is compared to the standard temperature. This index is favoured by the power industry to hedge against a cool summer in which less power needs to be generated compared to their expectations. This is a common contract in the US where power is required for air conditioning units and not so common in Europe where air conditioning in homes is 
less common (Douglas- Jones 2002a). The other indices in use include: Precipitation; Rainfall; Snowfall; Wind speed and direction; Maximum or minimum daily temperature; Sunshine; and Humidity. A wide range of other indices are also used to structure transactions that provide the most appropriate hedging mechanisms for end-users. Average temperature is another common index for non-energy applications. Some transactions are also based on size- Rs.5,000; Limit- Rs.1 million; Premium- Rs.150,000. so-called event indices, which count the number of times that temperature exceeds or falls below a defined threshold over the contract period. Similar indices are also used for other variables. They are cumulative rainfall or the number of days on which snowfall exceeds a defined level. All contracts have a defined start date and end date that constrain the period over which the underlying index is calculated. The most common terms in the market are November 1 through March 31 for winter season contracts and May 1 through September 30 for summer contracts, however there has been an increasing volume of trading in one month and one week contracts as the market has grown. Some contracts also specify variable index calculation procedures within the overall term- such as exclusion of weekends or double weighting on specific days to address individual end- user business exposures. The buyer of a weather option pays a premium to the seller that is typically between 10 and 20 percent of the notional amount of the contract. However, this can vary significantly depending on the risk profile of the contract. There is typically no upfront premium associated with swaps. A common form of weather derivative is a put option providing protection against a warm winter. Example: Reference weather station: New Delhi International Airport; Underlying index- Heating Degree Days; Term- November 1 March 31; Structure- Put option; Strike- 4850 HDDs; Tick size- Rs.5,000; Limit- Rs.1 million; Premium- Rs.150,000.

\section{BIBLIOGRAPHY}

[1] Brockett P. L., Wang M., Yang, C. (2005). "Weather Derivatives and Weather Risk Management", Risk Management and Insurance Review, Vol. 8 (1), pp. 127-140.

[2] Cao, M. and Wei, J. (2003). "Weather Derivatives: A New Class of Financial Instruments", Working paper, University of Toronto, Ontario, Canada.

[3] Considine G., (2000) "Introduction to Weather Derivatives", Weather Derivatives Group, Aquila Energy Downloaded from: http://www.cme.com/files/weatherde.pdf

[4] Dischel, R.S (2009), 'The Fledgling Weather Market Takes Off' Applied Derivative Trading Focus online magazine.

[5] Harwood, J., Heifner, R., Coble, K., Perry, J. and Somwaru, A. (1999), Managing Risk in Farming: Concepts, Research, and Analysis, Economic Research Service, Agricultural Economic Report No. 774, US Department of Agriculture.

[6] Hess, U. 2003. "Innovative Financial Services for Rural India: Monsoon-Indexed Lending and Insurance for Smallholders." Agriculture and Rural Development Working Paper No. 9. The World Bank, Washington, DC.

[7] Michael and Glantz, (2003), Climate Affairs: A http://books.google.co.uk/books?um=1\&q=tourisum+and+weather+derivatives\&btnG=Search+Books

[8] Turvey, C. G., 2001, "Weather Derivatives for Specific Event Risks in Agriculture", Review of Agricultural Economics, 23, 333-51.

[9] Skees, J., 2000, "A Role for Capital Markets in Natural Disasters: A Piece of the Food Security Puzzle", Food Policy, 25(3), pp. 365-78.

[10] Dercon, S., 2002, "Income Risk, Coping Strategies and Safety Nets", World Institute for Development Economics Research Discussion Paper 2002/22, Oxford.

\section{Author's Biography}

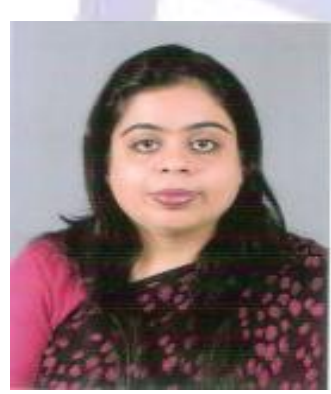

Neha Arora, PhD \& M.Phil in Management \& post graduate (Gold Medalist) from Lal Bahadur Institute of Management with in-depth knowledge on various subjects like Marketing of Services, Bank Management, Human Resource Accounting, Business Communication etc. She has been into recruitments and corporate attachments for five years and so. She has Provided Quality leadership and direction to the project management and team members. Comprehensive expertise in catalyzing / managing quality related operations with key focus on enhancing efficiency and effectiveness of end to end tasks. Ensured optimal utilization of resources and adherence with performance metrics. An active key member in implementing 360 degree performance appraisal system at Sobtis Group. She has also been recognized by IVRI Bareilly for her contributory work on analyzing the kisan metrics for new product growth. She has also been honoured to meet India Ex-President Dr. APJ Abdul Kalam as a representation from the college in Lal Bahadur Shastri Rashtriya Awards. She has also been authored for the articles and researcher papers in various journals. She has also been content writer for various revolutionary topics both in-house and outhouse books. 